\title{
The Impact of Perceived Discrimination on Mental Health Among Chinese Migrant and Left-Behind Children: A Meta-analysis
}

\author{
Yu Hu${ }^{1}$ D $\cdot$ Jingwen $\mathrm{Hu}^{1}$ D $\cdot \mathrm{Yi} \mathrm{Zhu}^{2}$ (D)
}

Accepted: 9 September 2021 /Published online: 30 September 2021

(c) The Author(s) 2021

\begin{abstract}
In China, rural-urban migration is one of major influences on the mental health of migrant and left-behind children. Literature suggests that the perception of discrimination is an important factor that influences the mental health of these children. The present research explores (1) whether migrant children and left-behind children are different in the relationship between the perception of discrimination and mental health, and (2) whether the relationship between the perception of discrimination and mental health of these children is moderated by gender and age. Using a metaanalytic technique, the authors included 26 studies (generating 48 independent samples) with a total sample size of 28,883 participants. Results showed that the perception of discrimination of migrant children was negatively correlated with positive indicators of mental health, and it has a stronger effect than left-behind children; the perception of discrimination of migrant children was positively correlated with negative indicators of mental health, and it has a weaker effect than left-behind children. Additionally, gender moderated the relationship between the perception of discrimination and the positive indicators of mental health among left-behind children, while age moderated such relationship among migrant children.
\end{abstract}

Keywords Discrimination perception · Migrant children · Left-behind children · Mental health

Yi Zhu

16187654@qq.com

1 Research Institute of Social Development, Southwestern University of Finance and Economics, Chengdu, People's Republic of China

2 School of Psychology, Shenzhen University, No. 3688 Nanhai Ave., Nanshan, Shenzhen, People's Republic of China 


\section{Introduction}

The past three decades have witnessed a process of rapid urbanization in China (Liang, 2016). A large number of laborers have engaged in an internal migration, mainly characterized by migration from rural areas to cities (Wu \& Zhang, 2015). Many young migrants have school-age children, and it is estimated that approximately 100 million children are affected by the internal migration. These children's health has been gaining increasing attention in recent years (Huang et al., 2018; Tan, 2011), because children's physical and mental health have enduring impacts on social mobility when they become adults (Palloni, 2006). The present research centers on the mental health problems in these children.

Children who are affected by the internal migration are known as migrant children and left-behind children. Migrant children are those who live temporarily with their parents or their guardians for more than half a year in a different place, whereas left-behind children are those with one or both parents leaving their hometown (usually rural areas) and working in cities (Fang et al., 2008). It is documented that these children suffer from discrimination associated with their identities (e.g., they are viewed as inferior to their counterparts who are born in cities) (Liu and Jacob, 2013). The perception of discrimination may affect negative and positive indicators of mental health (Branscombe et al., 1999). Perceived discrimination is defined as people's perception of being treated differently or unfairly due to their membership or classification within a certain group (e.g., household registration, race) (Major et al., 2002; Pascoe \& Richman, 2009). There is an increased interests in the relationship between perceived discrimination and mental health problem of migrant and left-behind children (Fan et al., 2016; Liu et al., 2013; Sun et al., 2016). Building on existing empirical studies, the present research uses a meta-analytic technique to further examine the relationship between perceived discrimination of children of migrants and positive and negative indicators of mental health, and explores whether the effect sizes between migrant and left-behind children are different. The present study also explores whether age and gender moderate the relation between perceived discrimination and mental health among these two groups of children.

\section{Perception of Discrimination and Mental Health}

From an ecological perspective, factors at different ecological levels influence children development. The "UNHAPPY" framework specifies a range of risk factors associated with cultural values, life dissatisfaction, poverty and social disadvantage, parenting problems, and schooling, and these risk factors contribute to negative children development (Shek \& Siu, 2019). This framework is helpful to understand why migrant and left-behind children are vulnerable to the internal migration. Migrant and left-behind children confront various risk factors, such as relatively low socioeconomic status, cultural and language barriers (Chan et al., 2009), lack of emotional support from parents ( $\mathrm{Li}$ et al., 2010), and household registration system (hukou) which affects the rights and benefits of these children (e.g., education opportunities, 
medical care) (Fan et al., 2016; Liang et al., 2019; Wu \& Zhang, 2015). Because of these disadvantages, migrant children and left-behind children suffer from stigmatization-they are sometimes rejected by other groups due to their unfavorable status, and they sometimes confront harmful attitudes and behaviors towards them (Shen et al., 2015).

Their perception of discrimination can affect mental health. According to the rejection identification model (RIM) proposed by Branscombe et al. (1999), the perception of discrimination has both positive and negative effects on mental health. More specifically, this model posits that an individual's perceived exclusion by an out-group may have differential impacts on them: the perception of discrimination promotes ingroup identification, which in turn protects their mental health, or leads to the awareness of their disadvantaged status, which negatively affecting mental health. Research suggests that the perception of discrimination indeed positively correlates with negative indicators of mental health (e.g., loneliness) (Fang et al., 2008; Hou et al., 2011).

Empirical research suggests that the perception of discrimination of migrant children leads to awareness of their disadvantaged status, which positively correlates with depression ( $\mathrm{Li}$ et al., 2018), social alienation (Zhang et al., 2017), and social anxiety (Lin et al., 2009; Mi, 2014), and that the perceived discrimination also hinders the development of positive emotions (Li et al., 2016). Some other studies suggest that perception of discrimination negatively correlates with the positive indicators of mental health (Liu et al., 2013; Xiao, 2017). With regard to left-behind children, literature suggests that left-behind children's perception of discrimination is also positively correlated with negative indicators of mental health, and negatively correlated with positive indicators of mental health (Liu et al., 2013; Zhao et al., 2016), and that the perception of discrimination is positively correlated with social alienation (Wang \& Sun, 2018) and negatively correlated with subjective well-being (Yu et al., 2018).

\section{The Present Study}

Both evolutionary perspective (Buss, 1995; Wood \& Eagly, 2002) and social role theory (Bandura, 1977; Eagly, 1987) point to gender differences in many characteristics and behaviors. It is reasonable to expect a gender difference in the perceptions of discrimination (Shen et al., 2015; Mi, 2014). For instance, Mi (2014) suggests that girls are more affected by perceived discrimination than boys since their scores on social anxiety and fear of negative evaluation are higher than boy. Other research suggests that there is no such significant gender difference (Lin et al., 2009). Thus extant findings are mixed in terms of gender difference in perceived discrimination and its mental health outcomes.

Next, relationship between perceived discrimination and mental health could be moderated by age. According to Brown and Bigler (2005), cognitive development plays an important role in shaping children's discrimination perception. That is, cognitive maturity ensures that children are able to perceive discrimination in different scenarios. Thus children's perception of discrimination changes with age, with 
higher sensitivity to discriminatory information and more mental health problem among older children, as compared with their younger counterparts (Wang et al., 2012). Therefore, building on previous research, the present research also aims to explore age as a moderator in the relationship between perceived discrimination and mental health.

Additionally, quality of life in children and adolescents in Chinese societies has been gaining increasing scholarly attention in recent year. For instance, a recent special issue contributes to our understanding of determinants of quality of life in children and adolescents in Chinese societies (Leung \& Fung, 2021). However, the papers in that special issue are mainly studies in Hong Kong and empirical studies on mainland China are inadequate.

Therefore, the present research uses a meta-analysis to further explore the relationship between perceived discrimination and mental health. Specifically, the present study asks (1) whether migrant children and left-behind children are different in the relationship between the perception of discrimination and mental health, and (2) whether the relationship between the perception of discrimination and mental health problem of migrant and left-behind children is moderated by gender and age respectively.

\section{Methods}

\section{Literature Search}

Literature included in the present research involves empirical studies that have been published in both Chinese and English journals. In order to search empirical articles that are most pertinent to the purpose of this research, the authors search literature via the following databases: Web of Science, PsycINFO, CNKI, and Wanfang. In addition, in previous research on mental health, scholars included two indicators of mental health, namely positive indicators (e.g., subjective well-being, life satisfaction, positive emotions) and negative indicators (e.g., loneliness, depression, anxiety, social alienation, negative emotions) (Hu et al., 2015; Liu et al., 2019; Suldo \& Shaffer, 2008). Thus in this research, both positive and negative indicators of mental health were included when assessing the relationship between perception of discrimination and the mental health of children. The authors used the following keywords when searching literature: migrant children and left-behind children, discrimination perception and perceived discrimination, and mental health, depression, loneliness, anxiety, negative emotions, subjective well-being, and positive emotions.

\section{Inclusion Criteria}

The following criteria were used to select articles: (1) Empirical studies that report quantitative results; meta-analysis and comprehensive research are excluded; (2) Correlation coefficient between children's perception of discrimination and mental 
health (including positive or negative indicators or both) must be reported; (3) The age range of participants must be 6-18 years, with the exclusion of other groups.

\section{Coding}

All independent samples in this study were coded. Table 1 includes information concerning name of author, sample size, gender, mean age, mental health type (i.e., positive and negative indicators of mental health), child type (migrant or left-behind children), and correlation coefficient.

\section{Data Analysis}

The CMA 2.0 (Comprehensive Meta-Analysis 2.0) was used for data analysis. Following previous research (Hu et al., 2015), the authors used a fixed-effects model to evaluate the average effect size and to do homogeneity test. Compared with randomeffects model, the fixed-effects model allows a more precise estimate of the relationship between perception of discrimination and mental health (Cooper, 1998). The fixed effect model also allows us to conduct comparative analysis within group and to make between-group comparison. Homogeneity tests (Q-tests) were adopted to determine potential moderators. This article used the correlation coefficient as the effect quantity.

Based on a rigorous literature search and filtering method described above, a total of 26 empirical studies were obtained for this meta-analysis. See Table 1 for original studies included in the meta-analysis. There were 28,883 participants included in these studies and 48 effect sizes were generated. Furthermore, there were 29 studies that included the analysis of correlations between children's perceived discrimination and negative indicators of mental health, and 19 studies that contained the analysis of correlations between children perceived discrimination and positive indicators of mental health. For studies on migrant children, 19 articles about the relationship of perceived discrimination and negative indicators showed a positive correlation $(\mathrm{r}=0.294)$ and 11 articles showed a negative correlation between the variables $(r=-0.329)$. In the studies on left-behind children, 10 articles showed positive correlation between the two variables $(r=0.467)$, and 8 articles showed a negative correlation $(\mathrm{r}=-0.266)$.

\section{Results}

\section{Overall Relation}

In this meta-analysis, the authors used the fixed-effects model to calculate the mean weighted effect sizes (r), sample sizes (k), 95\% confidence intervals, and total homogeneity statistics. The analysis with fixed-effects model showed a correlation between children's perception of discrimination and negative indicators 
Table 1 Original studies included in the meta-analysis

\begin{tabular}{|c|c|c|c|c|c|c|}
\hline Study & Sample size & Gender (female) & Mean age & Mental Health & Child Type & $\mathrm{R}$ \\
\hline Lin et al. (2009) & 1164 & 0.429 & 12.3 & $\mathrm{AX}$ & MB & 0.38 \\
\hline Lin et al. (2009) & 1164 & 0.429 & 12.3 & LP & MB & 0.5 \\
\hline Lin et al. (2009) & 1164 & 0.429 & 12.3 & DP & MB & 0.37 \\
\hline Hou et al. (2011) & 680 & 0.43 & & LP & MB & 0.42 \\
\hline Fang et al. (2008) & 1164 & 0.429 & 12.3 & LP & MB & 0.44 \\
\hline Li and Jiang (2018) & 504 & 0.548 & 12.36 & LP & MB & 0.35 \\
\hline Li and Jiang (2018) & 504 & 0.548 & 12.36 & DP & MB & 0.39 \\
\hline $\begin{array}{l}\text { Fan and Chen } \\
\text { (2012) }\end{array}$ & 558 & 0.453 & 12.25 & DP & MB & 0.463 \\
\hline Fan et al. (2016) & 507 & 0.453 & 12.25 & DP & MB & 0.42 \\
\hline Zhang et al. (2017) & 1101 & 0.447 & & SA & MB & 0.44 \\
\hline Mi (2014) & 197 & 0.569 & & $\mathrm{AX}$ & MB & 0.532 \\
\hline $\mathrm{Hu}(2012)$ & 817 & 0.463 & 12.67 & LP & MB & 0.216 \\
\hline Hu (2012) & 817 & 0.463 & 12.67 & DP & MB & 0.187 \\
\hline Lu (2012) & 239 & 0.464 & 12.61 & DP & MB & 0.675 \\
\hline Lu (2012) & 239 & 0.464 & 12.61 & LP & MB & 0.66 \\
\hline Wang et al. (2018) & 528 & 0.521 & & LP & LB & 0.566 \\
\hline Liu (2017) & 1703 & 0.47 & 13.43 & HP & LB & 0.51 \\
\hline Zhu (2017) & 512 & 0.492 & & HP & LB & 0.442 \\
\hline Zhao et al. (2016) & 1042 & 0.52 & 13.44 & PA & LB & 0.4 \\
\hline Zhao et al. (2016) & 1181 & 0.52 & 13.44 & NA & LB & 0.4 \\
\hline Zhao et al. (2016) & 1177 & 0.453 & 13.91 & LS & LB & 0.61 \\
\hline $\begin{array}{l}\text { Wang and Ding } \\
\text { (2003) }\end{array}$ & 813 & 0.445 & 12.56 & PA & MB & 0.22 \\
\hline Li and Jiang (2018) & 1898 & 0.46 & 12.82 & NA & MB & 0.47 \\
\hline Shi et al. (2013) & 559 & 0.467 & 12.83 & LS & MB & -0.28 \\
\hline Xing et al. (2011) & 1350 & 0.435 & 13.01 & LS & MB & -0.32 \\
\hline Liu et al. (2013) & 1551 & 0.466 & 13.01 & $\mathrm{HP}$ & MB & -0.34 \\
\hline Liu et al. (2013) & 1551 & 0.466 & 13.01 & NA & MB & 0.39 \\
\hline Liu et al. (2013) & 1551 & 0.466 & 13.01 & LS & MB & -0.33 \\
\hline Liu et al. (2013) & 1350 & 0.535 & 13.01 & HP & MB & -0.34 \\
\hline Liu et al. (2013) & 1350 & 0.535 & 13.01 & NA & MB & 0.39 \\
\hline Liu et al. (2013) & 1350 & 0.535 & 13.01 & PA & MB & -0.33 \\
\hline Lin et al. (2015) & 313 & 0.504 & & LS & MB & -0.304 \\
\hline Xiao (2017) & 345 & 0.498 & 13.69 & HP & MB & -0.33 \\
\hline Xiao (2017) & 345 & 0.498 & 13.69 & PA & MB & -0.12 \\
\hline Хiao (2017) & 345 & 0.498 & 13.69 & NA & MB & 0.31 \\
\hline Xiao (2017) & 345 & 0.498 & 13.69 & PA & MB & -0.26 \\
\hline Zhao et al. (2016) & 1181 & 0.53 & 13.44 & PA & LB & -0.302 \\
\hline $\begin{array}{l}\text { Fan and Shao } \\
\text { (2013) }\end{array}$ & 533 & 0.459 & 11.97 & PA & LB & -0.27 \\
\hline $\begin{array}{l}\text { Fan and Shao } \\
\text { (2013) }\end{array}$ & 533 & 0.459 & 11.97 & NA & LB & 0.36 \\
\hline
\end{tabular}


Table 1 (continued)

\begin{tabular}{llllllr}
\hline Study & Sample size & Gender (female) & Mean age & Mental Health & Child Type & R \\
\hline $\begin{array}{l}\text { Fan and Shao } \\
\quad \text { (2013) }\end{array}$ & 533 & 0.459 & 11.97 & LS & LB & -0.27 \\
$\begin{array}{l}\text { Shen et al., (2009a, } \\
\text { 2009b) }\end{array}$ & 93 & 0.531 & 12.07 & HP & LB & 0.47 \\
$\begin{array}{l}\text { Shen et al., (2009a, } \\
\text { 2009b) }\end{array}$ & 219 & 0.531 & 12.07 & SA & LB & -0.36 \\
$\begin{array}{l}\text { Shen et al., (2009a, } \\
\text { 2009b) }\end{array}$ & 219 & 0.531 & & & LB & 0.39 \\
Shen et al., (2009a, & 219 & & & & & \\
$\quad$ 2009b) & & & & & & \\
He (2014) & 543 & 0.531 & 12.07 & DP & LB & -0.27 \\
He (2014) & 543 & 0.353 & 13.43 & PA & LB & -0.272 \\
He (2014) & 543 & 0.353 & 13.43 & NA & LB & 0.287 \\
Yu et al. (2018) & 374 & 0.571 & 13.43 & LS & LB & -0.104 \\
\hline
\end{tabular}

$L B$ left-behind children, $M B$ migrant children, $A X$ social anxiety, $D P$ depression, $S A$ social alienation, $L N$ loneliness, $N a$ negative emotion, $P A$ positive emotion, $L S$ life satisfaction, $H P$ subjective well-being

of mental health $(\mathrm{r}=0.352,95 \% \mathrm{CI}=[0.341,0.363])$. The correlation coefficients for migrant $(\mathrm{r}=0.294,95 \% \mathrm{CI}=[0.280,0.308])$ and left-behind children $(\mathrm{r}=0.467,95 \% \mathrm{CI}=[0.450,0.485])$ were significant. Results also showed a correlation between children's perception of discrimination and positive indicators of mental health $(\mathrm{r}=-0.310,95 \% \mathrm{CI}=[-0.325,-0.294])$. The correlation

Table 2 Results of fix effect model

\begin{tabular}{|c|c|c|c|c|c|c|c|c|}
\hline \multirow{2}{*}{$\begin{array}{l}\text { Mental } \\
\text { health }\end{array}$} & \multirow{2}{*}{$\begin{array}{l}\text { Between- } \\
\text { group effect } \\
(\mathrm{QBET})\end{array}$} & \multirow[t]{2}{*}{$\mathrm{K}$} & \multirow[t]{2}{*}{$\mathrm{N}$} & \multicolumn{3}{|c|}{ Effect size and $95 \%$ interval } & \multicolumn{2}{|c|}{ Test of null [2-tail] } \\
\hline & & & & $\begin{array}{l}\text { Point esti- } \\
\text { mate }\end{array}$ & Lower limit & Upper limit & z-value & $\mathrm{p}$ value \\
\hline PI & $13.529 * * *$ & 19 & 8557 & -0.310 & -0.325 & -0.294 & -37.065 & $<0.001$ \\
\hline MB & & 11 & 5707 & -0.329 & -0.347 & -0.311 & -32.877 & $<0.001$ \\
\hline LB & & 8 & 2850 & -0.266 & -0.294 & -0.238 & -17.505 & $<0.001$ \\
\hline NI & $215.786 * * *$ & 29 & 20,346 & 0.352 & 0.341 & 0.363 & 57.087 & $<0.001$ \\
\hline MB & & 19 & 12,888 & 0.294 & 0.280 & 0.308 & 38.937 & $<0.001$ \\
\hline LB & & 10 & 7438 & 0.467 & 0.450 & 0.485 & 44.256 & $<0.001$ \\
\hline \multicolumn{9}{|l|}{ Overall } \\
\hline PI & & 19 & 8557 & -0.310 & -0.325 & -0.294 & -37.065 & $<0.001$ \\
\hline NI & & 29 & 20,346 & 0.352 & 0.341 & 0.363 & 57.087 & $<0.001$ \\
\hline
\end{tabular}

$P I$ positive indicators, $N I$ negative indicators, $M B$ migrant children, $L B$ left-behind children

**** $p<0.001$ 


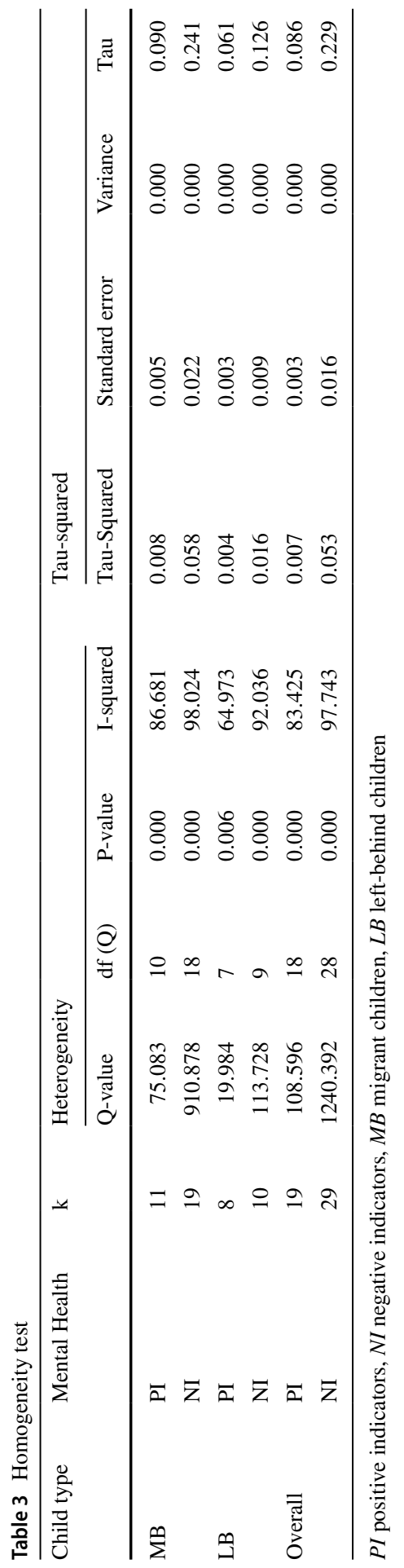




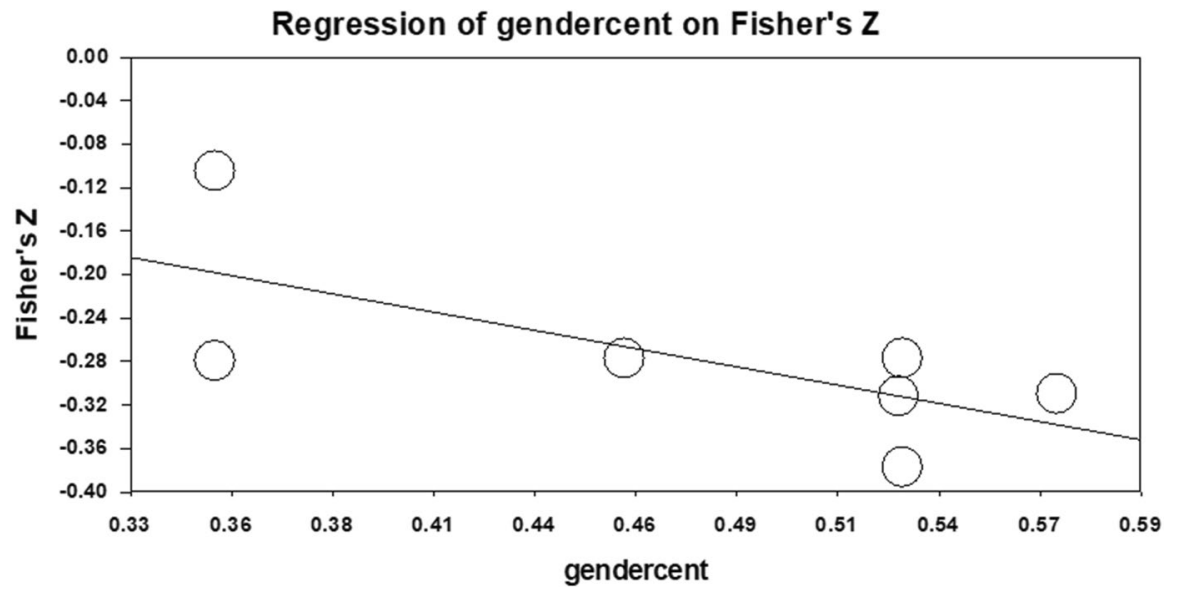

Fig. 1 Adjustment of gender to PI of LB

coefficients for migrant $(\mathrm{r}=-0.329,95 \% \mathrm{CI}=[-0.347,-0.311])$ and leftbehind children $(r=-0.266,95 \% \mathrm{CI}=[-0.294,-0.238])$ were significant.

To test whether there is differences between migrant and left-behind children, a between-group effect test was performed. Results were shown in Tables 2 and 3. We found significant differences between migrant and left-behind children in terms of positive and negative indicators of mental health (Figs. 1, 2).

\section{Analyses of Moderating Effect}

Meta-regression was used to test whether gender and age moderate the relationship between perception of discrimination and mental health. Results were shown in Table 4. Results showed that gender moderated the relationship between

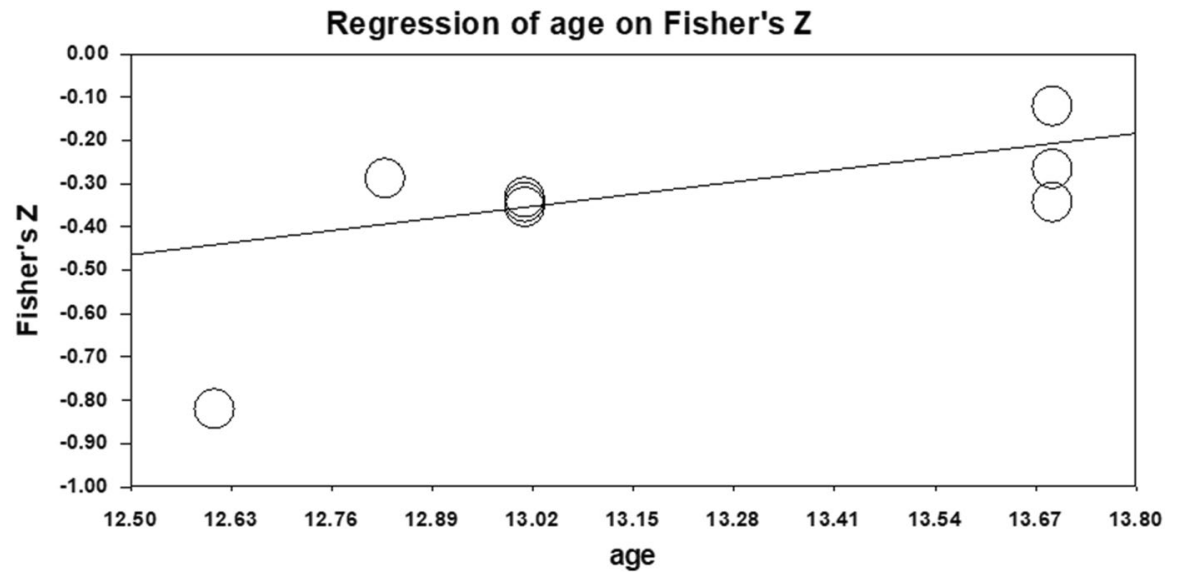

Fig. 2 Adjustment of age to PI of MB 
Table 4 Meta-regression analysis of children subtypes and positive indicators

\begin{tabular}{|c|c|c|c|c|c|c|c|c|}
\hline \multirow[t]{2}{*}{ Adjustment } & \multicolumn{4}{|c|}{ MB } & \multicolumn{4}{|c|}{ LB } \\
\hline & $\mathrm{K}$ & Slope & Q & $\mathrm{P}$ & $\mathrm{K}$ & Slope & Q & $\mathrm{P}$ \\
\hline \multicolumn{9}{|l|}{ PI } \\
\hline Gender & 11 & 1.00 & 0.91 & 0.34 & 8 & -0.64 & 5.72 & $0.016^{*}$ \\
\hline Age & 9 & 0.27 & 11.09 & $<0.001 * * *$ & 8 & 0.03 & 1.07 & 0.30 \\
\hline
\end{tabular}

$* p<.05, * * * p<.001$

perception of discrimination and positive indicators of mental health in leftbehind children (slope $=-0.64$, qmodel $=5.72, p=0.016$ ), suggesting that as the percentage of females increased, a weaker effect. With regard to age, results showed that age also moderated the relationship between perception of discrimination and positive indicators of mental health on migrant children (slope $=0.27$, qmodel $=11.09, p<0.001)$, suggesting that as age increased, a stronger effect (Table 5).

\section{Publication Bias Test}

To check publication bias of the meta-analysis, a funnel diagram was used. Figure 3 shows that the articles that were included in the present study were evenly and symmetrically distributed on both sides of the total effect quantity and concentrated on the top, indicating that the research bias of the relationship between children's perceived discrimination and mental health was not obvious. The funnel chart was a preliminary test of published bias, so in order to have a more accurate test of publication bias, the authors used the classic Failsafe-N and Egger's test. Results showed a large number of unpublished research reports $(>6200)$ are needed to reverse the conclusion of this meta-analysis, indicating that the results are relatively stable. Moreover, results of the Egger's test showed that there was no significant difference $(\mathrm{t}=0.025, p>0.05)$, indicating that this meta-analysis was not affected by publication bias.

Table 5 Meta-regression analysis of children subtypes and negative indicators

\begin{tabular}{|c|c|c|c|c|c|c|c|c|}
\hline \multirow[t]{2}{*}{ Adjustment } & \multicolumn{4}{|c|}{ MB } & \multicolumn{4}{|l|}{ LB } \\
\hline & $\mathrm{K}$ & Slope & Q & $\mathrm{P}$ & $\mathrm{K}$ & Slope & Q & $\mathrm{P}$ \\
\hline \multicolumn{9}{|l|}{ NI } \\
\hline Gender & 18 & 0.74 & 0.32 & 0.57 & 11 & 0.67 & 0.60 & 0.44 \\
\hline Age & 16 & -0.13 & 1.12 & 0.29 & 7 & 0.001 & 0.008 & 0.92 \\
\hline
\end{tabular}




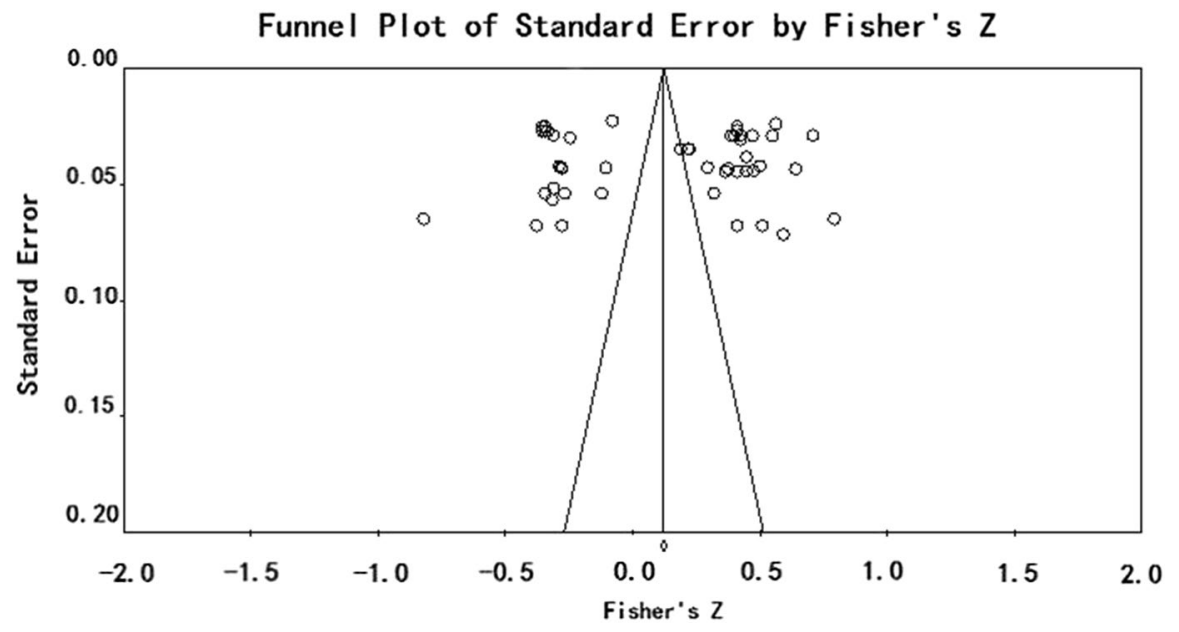

Fig. 3 Funnel chart of mental health indictors

\section{Discussion}

Mental health problems in migrant and left-behind children has been gaining increasing attention in recent years (Huang et al., 2018)This meta-analysis aims to have better understanding of the relationship between the perception of discrimination and mental health of migrant and left-behind children. This study found that (1) the correlation between the two variables was significant, (2) the correlations between the two variables were significantly different between migrant and leftbehind children, and (3) this relationship was moderated by gender and age.

The perception of discrimination of migrant and left-behind children was negatively correlated with positive indicators of mental health and positively correlated with negative indicators, thus consistent with previous studies (Lin et al., 2009; Fan et al., 2012). This finding suggests that the perception of discrimination was a major cause of mental health problems. Indeed, perceived discrimination brings with it a range of negative effects to disadvantaged groups, such as difficulties in coping with stress (Lazarus, 1984) and learned helplessness (Ruggiero \&Taylor, 1997). When disadvantaged groups feel that they are being discriminated based on dangerous information and due to uncontrollable events, this causes a series of psychological problems. Thus, our meta-analysis supports the idea that perception of discrimination reduces happiness in members of disadvantaged groups.

Our results also showed a difference between migrant and left-behind children. Specifically, the correlation between perception of discrimination and negative indicators of mental health in left-behind children was stronger than that in migrant children, the correlation between perception of discrimination and positive mental health indicators in left-behind children was weaker than that in migrant children. Based on symbolic interactionism, people rely on the feedback and evaluation of others to establish their own self-concept. Individuals who have experienced discriminations for a long period of time internalize such discriminations and 
eventually affect their own opinions, thereby negatively affecting their mental health. This is consistent with the self-realization prediction effect (Darley \& Fazio, 1980). Left-behind children are consistently being stereotyped, and they have internalized stereotypes, which subsequently causes their mental health problems (Zhao et al., 2016). For instance, Fan and Sang (2005) suggests that left-behind children's cores on mental illness were significantly higher compared to other groups. From ecological perspective, family is regarded as a key environment for children development (Bronfenbrenner, 1986). Family is a complex ecosystem in which the parental subsystem is an important factor in influencing children's mental health (Xi et al., 2004; Li et al., 2010), and positive family relationships will create a favorable environment for the successful adjustment of children (Steinberg, 2001). Family ecosystem substantially changes when parents engage in the internal migration, and such change may have negative impacts on their children (Xu \& Zhang, 2016). Compared with migrant children, left-behind children lack family care (Hou \& Ao, 2019) and have fewer emotional communication with their parents (Ye et al., 2006). All these factors may result in the difference between migrant and left-behind children.

Additionally, another interesting finding of this article was that gender and age moderated the relationship between perception of discrimination and positive mental health indicators on left-behind children. Compared with females, this correlation in males was stronger, consistent with previous research (e.g., Wang, 2012). This observation suggests that males were more sensitive to perceived discrimination, and their positive mental health indicators (e.g., subjective well-being, positive emotions, life satisfaction) were more influenced by their perception of discrimination. Therefore, the overall well-being of females was significantly higher than males (Wang \& Ding, 2003). On the other hand, age also moderated the relationship between perception of discrimination and positive mental health indicators of migrant children. Specifically, results showed that the correlation between perception of discrimination and positive indicators of mental health increased with age. That is, compared with younger migrant children, older migrant children's positive indicators of mental health (e.g., subjective well-being, positive emotions, life satisfaction) were more likely to be reduced by their perceived discrimination. This finding was consistent with previous research (Liu, 2013). Children's self-awareness develops with age (Deng and Shi, 2013), and the development of self-awareness may cause migrant children to become more sensitive to their unfair situation. In addition, migrant children in junior high school may face more uncertainty, agitation, and confusion in both physical and mental aspects, as well as greater learning pressure (Deng and Shi, 2013). Thus, older children's perception of discrimination more likely affects the positive indicators of mental health, as compared to younger children.

Finally, our findings have important practical implications for designing intervention program to promote healthy development of migrant and left-behind children. On one hand, given that the perception of discrimination leads to awareness of disadvantaged status, which associates with negative indicators of mental health of these children, including depression, social alienation, and social anxiety, effective community education and school education about correct understanding about leftbehind and migrant children should be promoted, so as to reduce prejudice about 
left-behind and migrant children. On the other hand, attempts should be made to promote the mental health and well-being of migrant and left-behind children and adolescents. Project P.A.T.H.S. in Hong Kong is illuminating in attempts to design interventions to improve mental health of these children. It is a community-based positive youth development (PYD) program which aim to cultivate and enhance youths' PYD attributes, enabling them to cope with developmental challenges in an adaptive manner and maintain healthy functioning. The PYD approach focuses on equipping children and adolescent with multiple psychological competencies such as resilience, emotional skills, and moral competence (Shek et al., 2019). Recent research provides empirical support for the effectiveness of the PYD program in the Chinese context (Ma et al., 2019; Shek \& Zhu, 2020; Zhu \& Shek, 2020). Therefore, programs modeled from PYD approach is expected to be effective in promoting mental health and well-being of migrant and left-behind children.

\section{Limitations and Future Research}

Our meta-analysis has some limitations. First, since all the analyses were on the basis of existing empirical studies, this study failed to consider other possible moderators (e.g., self-esteem, family economic status, coping strategies), which may also influence the relationship between perception of discrimination and mental health of migrant and left-behind children. Second, the perception of discrimination of migrant and left-behind children is a dynamic process. Thus, with changes over time, the relationship between children's perception of discrimination and other indicators would also change. However, the literature that we included in this study basically amounted to a cross-sectional study, thus lacking longitudinal information. Third, this meta-analysis only considered left-behind and migrant children in China. Future research might consider including other groups of children (e.g., disabled or urban children) for additional comparisons.

Funding This paper was financially supported by the Guang Hua Young Teacher Development Program of Southwestern University of Finance and Economics, China.

\section{Declarations}

Conflict of interest The authors declare that they have no conflict of interests.

Open Access This article is licensed under a Creative Commons Attribution 4.0 International License, which permits use, sharing, adaptation, distribution and reproduction in any medium or format, as long as you give appropriate credit to the original author(s) and the source, provide a link to the Creative Commons licence, and indicate if changes were made. The images or other third party material in this article are included in the article's Creative Commons licence, unless indicated otherwise in a credit line to the material. If material is not included in the article's Creative Commons licence and your intended use is not permitted by statutory regulation or exceeds the permitted use, you will need to obtain permission directly from the copyright holder. To view a copy of this licence, visit http://creativecommons.org/licen ses/by/4.0/. 


\section{References}

Bandura, A. (1977). Social learning theory (pp. 20-21). Elsevier Science.

Branscombe, N. R., Schmitt, M. T., \& Harvey, R. (1999). Perceiving pervasive discrimination among African Americans: implications for group identification and well-being. Journal of Personality and Social Psychology, 77(1), 135-149. https://doi.org/10.1037//0022-3514.77.1.135.

Bronfenbrenner, U. (1986). Ecology of the family as a context for human development: Research perspectives. Developmental Psychology, 22(6), 723-742. https://doi.org/10.1037/0012-1649.22.6.723

Brown, C. S., \& Bigler, R. S. (2005). Children's perceptions of discrimination: A developmental model. Child Development, 76(3), 533-553. https://doi.org/10.1111/j.1467-8624.2005.00862.x

Buss, D. M. (1995). Psychological sex differences: Origins through sexual selection. American Psychologist, 50(3), 164-168. https://doi.org/10.1037/0003-066X.50.3.164

Chan, E., Mercer, S. W., Yue, C., Wong, S., \& Griffiths, S. M. (2009). Mental health of migrant children: An overview of the literature. International Journal of Mental Health, 38(3), 44-52. https://doi.org/ 10.2753/IMH0020-7411380303

Cooper, H. M. (1998). Synthesizing research: A guide for literature reviews (Vol. 2). Sage.

Darley, J. M., \& Fazio, R. H. (1980). Expectancy confirmation processes arising in the social interaction sequence. American Psychologist, 35(10), 867-881. https://doi.org/10.1037/0003-066X.35.10.867

Deng, X., \& Shi, B. (2013). Migrant children' s perceived discrimination and self-esteem the effect of social support and migration duration. Chinese Journal of Special Education, 8, 48-54. https://doi. org/10.3969/j.issn.1007-3728.2013.08.009.

Eagly, A. H. (1987). Sex differences in social behavior: A social-role interpretation (pp. 47-49). Psychology Press.

Fan, F., \& Sang, B. (2005). Lack of parent-child education and personality, academic performance and behavior problems of "left-behind children." Psychological Science, 4, 855-858. https://doi.org/10. 16719/j.cnki.1671-6981.2005.04.022

Fan, X., \& Chen, F. (2012). Perceived discrimination and depression: moderating of coping, and social support in migrant children. Chinese Journal of Clinical Psychology, 20(4), 539-542. http://www. cnki.com.cn/article/cjfdtotal-zlcy201204030.htm.

Fan, L. H., \& Shao, J. L. (2013). Family economic status and subjective well-being of left-behind children: The mediating role of discriminatory perception. Journal of Guizhou Normal University (natural Science Edition), 31(06), 32-36. https://doi.org/10.16614/j.cnki.issn1004-5570.2013.06.012

Fan, X. H., Chen, F. J., Tang, W. P., Huang, Y. S., \& Yuan, S. Y. (2016). The dynamic relationship between discrimination perception, self-esteem and depression in migrant children: Model test. Chinese Journal of Clinical Psychology, 24(1), 45-48. https://doi.org/10.16128/j.cnki.1005-3611.2016. 01.010

Fang, X. Y., Fan, X. H., \& Liu, Y. (2008). Moderating effects of coping styles on the relationship between migrant children's perception of discrimination and loneliness. Psychological Development and Education, 4, 93-99. https://doi.org/10.16187/j.cnki.issn1001-4918.2008.04.011

He, D. (2014). The relationship between left-behind children's perception of discrimination, psychological flexibility and subjective well-being (Master's thesis), Jiangxi Normal University, China.

Hou, F. X., \& Ao, J. S. (2019). Comparison of family functions of left-behind children and migrant children and their influencing factors. Famous Doctors, 4, 94.

Hou, S. D., Yuan, X. J., Liu, Y., Xiu, Y. Y., \& Fang, X. Y. (2011). The impact of social support and perception of discrimination on migrant children's loneliness: A follow-up study. Psychological Development and Education, 27(4), 401-411. https://doi.org/10.16187/j.cnki.issn1001-4918.2011.04.012

Hu, F. F. (2012). Study on the Relationship between perception of discrimination and psychological adaptation of migrant children and its impact mechanism (Master's thesis), Anhui Normal University, China. https://kns.cnki.net/KCMS/detail/detail.aspx?dbname=CMFD201301\&filename= 1012506550.nh.

Hu, T., Zhang, D., \& Wang, J. (2015). A meta-analysis of the trait resilience and mental health. Personality and Individual Differences, 76, 18-27. https://doi.org/10.1016/j.paid.2014.11.039

Huang, Y., Song, Q., Tao, R., \& Liang, Z. (2018). Migration, family arrangement, and children's health in China. Child Development, 89(2), e74-e90. https://doi.org/10.1111/cdev.12699

Leung, J. T. Y., \& Fung, A. L. (2021). Editorial: Special issue on quality of life among children and adolescents in Chinese societies. Applied Research Quality Life. https://doi.org/10.1007/ s11482-021-09915-9 
Li, C. K., \& Jiang, S. (2018). Social exclusion, sense of school belonging and mental health of migrant children in China: A structural equation modeling analysis. Children and Youth Services Review, 89, 6-12. https://doi.org/10.1016/j.childyouth.2018.04.017

Li, X. W., Liu, Y., \& Qu, Z. Y. (2010). The status of family ecosystems in different types of rural children and their impact on child self-esteem. Chinese Journal of Clinical Psychology, 18(2), 241-243. https://doi.org/10.16128/j.cnki.1005-3611.2010.02.036

Li, X. Y., Zhang, X. L., \& Shi, J. N. (2016). The development of migrant children's self-concept and its relationship with mental health. Psychology and Behavior Research, 14(1), 116-121.

Li, Y., Ma, Z. Q., \& Zhang, L. (2018). The effect of migrant children's perception of discrimination on depressive symptoms: The mediating role of social support and loneliness. Modern Preventive Medicine, 45(5), 832-834.

Liang, Z. (2016). China's great migration. Annual Review of Sociology, 42, 451-471. https://doi.org/10. 1097/SCS.0000000000000611

Liang, Z., Yue, Z. S., Li, Y. F., Li, Q., \& Zhou, A. H. (2019). Choices or constraints, education of migrant children in China. Population Research and Policy Review., 39(4), 671-690. https://doi.org/10.1007/ s11113-019-09564-9

Lin, L. Z., Chen, X. Y., Lin, L. H., Kang, Y. L., \& Huang, T. T. (2015). The impact of migrant children's perceived discrimination on subjective well-being: The mediating role of self-concealment. Journal of Shenyang Institute of Technology, 11(1), 26-30.

Lin, X. Y., Fang, X. Y., Liu, Y., \& Lan, J. (2009). The relationship between migrant children's perception of discrimination and their mental health and its psychological mechanism. Acta Psychologica Sinica, 41(10), 967-979.

Liu, X. (2017). Perception of discrimination and depression in rural left-behind children: The mediating role of friendship quality (Master's thesis), Shandong Normal University, China.

Liu, J., \& Jacob, W. J. (2013). From access to quality: Migrant children's education in urban China. Education Research for Policy Practice, 12(3), 177-191. https://doi.org/10.1007/s10671-012-9136-y

Liu, W., Yu, Z. Y., \& Lin, D. H. (2019). Resilience and mental health in children and youth: A metaanalysis. A meta-analysis of the relationship between psychological resilience and mental health in children and adolescents. Research in Psychology and Behavior, 17(1), 31-37.

Liu, X., Zhao, J. X., \& Shen, J. L. (2013). The impact of perceived discrimination on the well-being of urban migrant children: Mediating mechanisms and moderating roles of attribution needs. Acta Psychologica Sinica, 45(5), 568-584. https://doi.org/10.3724/SP.J.1041.2013.00568

Lu, X. (2012). Migrant children's perception of discrimination and psychological adaptation: The role of social support (Master's thesis), Hunan University of Science and Technology, China.

Ma, C. M. S., Shek, D. T. L., \& Chen, J. M. T. (2019). Changes in the participants in a communitybased positive youth development program in Hong Kong: Objective outcome evaluation using a one-group pretest-posttest design. Applied Research Quality Life, 14(4), 961-979. https://doi.org/10. 1007/s11482-018-9632-1

Major, B., Quinton, W., \& McCoy, S. (2002). Antecedents and consequences of attributions to discrimination: Theoretical and empirical advances. In M. P. Zanna (Ed.), Advances in Experimental Social Psychology (Vol. 34, pp. 251-329). Academic Press.

Mi, C. (2014). The relationship between migrant children's perception of discrimination and social anxiety and its intervention (Master's thesis), Guangxi Normal University, China.

Palloni, A. (2006). Reproducing inequalities: Luck, wallets, and the enduring effects of childhood health. Demography, 43, 587-615. https://doi.org/10.1353/dem.2006.0036

Pascoe, E. A., \& Richman, L. S. (2009). Perceived discrimination and health: A meta-analytic review. Psychological Bulletin, 135(4), 531-554. https://doi.org/10.1037/a0016059

Ruggiero, K. M., \& Taylor, D. M. (1997). Why minority group members perceive or do not perceive the discrimination that confronts them: The role of self-esteem and perceived control. Journal of Personality \& Social Psychology, 72(2), 373-389. https://doi.org/10.1037/0022-3514.72.2.373

Shek, D. T. L., Dou, D., Zhu, X., \& Chai, W. (2019). Positive youth development: Current perspectives. Adolescent Health, Medicine and Therapeutics, 10, 131-141. https://doi.org/10.2147/AHMT.S1799 46

Shek, D. T. L., \& Siu, A. M. H. (2019). "UNHAPPY” environment for adolescent development in Hong Kong [Editorial]. Journal of Adolescent Health, 64(6, Suppl), S1-S4. https://doi.org/10.1016/j. jadohealth.2019.01.007 
Shek, D. T. L., \& Zhu, X. Q. (2020). Promotion of thriving among Hong Kong Chinese adolescents: Evidence from eight-wave data. Research on Social Work Practice, 30(8), 104973152094715. https:// doi.org/10.1177/1049731520947156

Shen, J. L., Hu, X. Y., \& Liu, X. (2009a). The characteristics of left-behind children's discrimination and their relationship with subjective well-being. Journal of Henan University (social Science Edition), 49(6), 116-121. https://doi.org/10.3969/j.issn.1000-5242.2009.06.020

Shen, J. L., Hu, X. Y., \& Liu, X. (2009b). The characteristics of left-behind children's perception of discrimination and their relationship with subjective well-being. Journal of Henan University (social Science Edition), 49(6), 116-121. https://doi.org/10.15991/j.cnki.411028.2009.06.018

Shen, J. L., Liu, X., Zhao, J. X., \& Shi, B. G. (2015). Research on the psychological development of migrant workers' children in the process of urbanization. Psychological Development and Education, 31(1), 108-116. https://doi.org/10.16187/j.cnki.issn1001-4918.2015.01.15

Shi, B. G., Deng, X. Q., \& Liu, X. (2013). Migrant children's well-being, perception of discrimination, and their relationships in public schools. Journal of Capital Normal University (social Science Edition), 3, 143-149. https://doi.org/10.3969/j.issn.1004-9142.2013.03.022

Steinberg, L. (2001). We know some things: Parent-adolescent relationships in retrospect and prospect. Journal of Research on Adolescence, 11, 1-19. https://doi.org/10.1111/1532-7795.00001

Suldo, S. M., \& Shaffer, E. J. (2008). Looking beyond psychopathology: The dual factor model of mental health in youth. School Psychology Review, 37, 52-68. https://doi.org/10.1080/02796015.2008. 12087908

Sun, X., Chen, M., \& Chan, K. L. (2016). A meta-analysis of the impacts of internal migration on child health outcomes in china. BMC Public Health, 16, 66. https://doi.org/10.1186/s12889-016-2738-1

Tan, S. (2011). A review of studies on left-behind children in rural china. Social Sciences in China, 1, $138-150$.

Wang, Y. (2012). Research on the relationship between Psychological Resilience, Rearing Styles and Academic Achievement of Junior Middle School Students (Master's thesis), East China Normal University, China.

Wang, J. S., \& Ding, X. H. (2003). A study on the relationship between subjective well-being and parental rearing patterns of junior middle school students in Beijing. China Health Education, 19(11), 868-869. https://doi.org/10.16168/j.cnki.issn.1002-9982.2003.11.024

Wang, J. L., Hsieh, H. F., Assari, S., Gaskin, J., \& Rost, D. H. (2018). The protective effects of social support and engagement coping strategy on the relationship between perceived discrimination and psychological distress among Chinese migrant children. Youth \& Society, 50(5), 593-614. https:// doi.org/10.1177/0044118x15619804

Wang, M. Z., Fan, C. Y., \& Zhou, Z. K. (2012). Review of perceived models of child discrimination. Exploration of Psychology, 4, 16-22.

Wang, Y. H., \& Sun, B. (2018). The mediating role of psychological flexibility of left-behind junior high school students between discrimination and social alienation. School Health in China, 39(2), 292295. https://doi.org/10.16835/j.cnki.1000-9817.2018.02.040

Wood, W., \& Eagly, A. H. (2002). A cross-cultural analysis of the behavior of women and men: Implications for the origins of sex differences. Psychological Bulletin, 128(5), 699-727. https://doi.org/10. 1037/0033-2909.128.5.699

Wu, X. G., \& Zhang, Z. (2015). Population migration and children's school enrollment in China, 19902005. Social Science Research, 53, 177-190. https://doi.org/10.1016/j.ssresearch.2015.05.007

Xi, J. Z., Sang, B., \& Deng, C. Q. (2004). A study on the characteristics of family ecosystem of children's mental health development. Psychological Science, 27(1), 72-76. https://doi.org/10.16719/j.cnki. 1671-6981.2004.01.019

Xiao, Q. Y. (2017). The relationship between migrant children's perceived discrimination and subjective well-being: The mediating role of fair world faith (Master's thesis), Hunan University of Science and Technology, China.

Xing, S. F., Liu, X., Zhao, J. X., \& Shi, B. G. (2011). The impact of perception of discrimination on the happiness of migrant children and its internal mechanisms. Psychological Development and Education, 27(6), 654-661. https://doi.org/10.16187/j.cnki.issn1001-4918.2011.06.015

Xu, X. X., \& Zhang, X. L. (2016). Incorporating a family perspective into public policy: An analysis based on the evolution of compulsory education policies for migrant children. Social Sciences in China, 6, 151-169. 
Ye, M., Zhang, J. P., \& He, D. R. (2006). Analysis of influential factors of left-behind children's mental health and countermeasures. Medicine and Philosophy (humanities and Social Medicine Edition), 6, 67-69.

Yu, X. Y., Feng, Y. Y., Yue, B., Liu, H. B., Zhang, S. H., Ku, X. F., \& Zheng, X. B. (2018). The mediating effect of social support on the perception of discrimination and subjective well-being of leftbehind children. Journal of North China University of Technology (medical Edition), 20(2), 148152. https://doi.org/10.19539/j.cnki.2095-2694.2018.02.014

Zhang, T. (2017). Perceived discrimination and loneliness of left-behind children in rural areas: The role of parent-child separation age and parent-child separation time (Master's thesis), Shandong Normal University, China.

Zhang, Y., Du, A. Z., Tan, D. L., Lei, T. T., \& Zhou, Y. G. (2017). The relationship between perception of discrimination and social alienation of migrant children: A moderated mediation model. Psychological Development and Education, 33(6), 719-726. https://doi.org/10.16187/j.cnki.issn10014918.2017.06.10

Zhao, J. X., Yang, P., Ma, J. L., \& Huang, C. C. (2016). The relationship between discriminatory perception and positive or negative emotions of left-behind children in rural areas: The protective role of parent-child affinity. Psychological Development and Education, 138(3), 116-123. https://doi.org/ 10.16187/j.cnki.issn1001-4918.2016.03.14

Zhu, S. S. (2017). Research on the Relationship between Perceived Discrimination, Coping Style and Loneliness of Left-behind Children (Master's thesis), Chongqing Normal University, China.

Zhu, X., \& Shek, D. T. L. (2020). Impact of a positive youth development program on junior high school students in mainland China: A pioneer study. Children and Youth Services Review, 114, 105022. https://doi.org/10.1016/j.childyouth.2020.105022

Publisher's Note Springer Nature remains neutral with regard to jurisdictional claims in published maps and institutional affiliations. 